\title{
Twelve-Month Prevalence of and Risk Factors for Suicide Attempts in the World Health Organization World Mental Health Surveys
}

\author{
Guilherme Borges, ScD; Matthew K. Nock, PhD; Josep M. Haro Abad, MD, PhD; \\ Irving Hwang, MA; Nancy A. Sampson, BA; Jordi Alonso, MD, MPH, PhD; \\ Laura Helena Andrade, MD, PhD; Matthias C. Angermeyer, PhD; Annette Beautrais, PhD; \\ Evelyn Bromet, PhD; Ronny Bruffaerts, PhD; Giovanni de Girolamo, MD; Silvia Florescu, MD; \\ Oye Gureje, MD, PhD, FRCPsych; Chiyi Hu, MD, PhD; Elie G. Karam, MD; \\ Viviane Kovess-Masfety, MD, PhD; Sing Lee, MBBS, FRCPsych; Daphna Levinson, PhD; \\ Maria Elena Medina-Mora, PhD; Johan Ormel, PhD; Jose Posada-Villa, MD; Rajesh Sagar, MD; \\ Toma Tomov, PhD; Hidenori Uda, MD; David R. Williams, PhD, MPH; and Ronald C. Kessler, PhD
}

\begin{abstract}
Objective: Although suicide is a leading cause of death worldwide, clinicians and researchers lack a data-driven method to assess the risk of suicide attempts. This study reports the results of an analysis of a large cross-national epidemiologic survey database that estimates the 12-month prevalence of suicidal behaviors, identifies risk factors for suicide attempts, and combines these factors to create a risk index for 12-month suicide attempts separately for developed and developing countries.
\end{abstract}

Method: Data come from the World Health Organization (WHO) World Mental Health (WMH) Surveys (conducted 2001-2007), in which 108,705 adults from 21 countries were interviewed using the WHO Composite International Diagnostic Interview. The survey assessed suicidal behaviors and potential risk factors across multiple domains, including sociodemographic characteristics, parent psychopathology, childhood adversities, DSM-IV disorders, and history of suicidal behavior.

Results: Twelve-month prevalence estimates of suicide ideation, plans, and attempts are $2.0 \%, 0.6 \%$, and $0.3 \%$, respectively, for developed countries and $2.1 \%$, $0.7 \%$, and $0.4 \%$, respectively, for developing countries. Risk factors for suicidal behaviors in both developed and developing countries include female sex, younger age, lower education and income, unmarried status, unemployment, parent psychopathology, childhood adversities, and presence of diverse 12-month DSM$I V$ mental disorders. Combining risk factors from multiple domains produced risk indices that accurately predicted 12 -month suicide attempts in both developed and developing countries (area under the receiver operating characteristic curve $=0.74-0.80$ ).

Conclusions: Suicidal behaviors occur at similar rates in both developed and developing countries. Risk indices assessing multiple domains can predict suicide attempts with fairly good accuracy and may be useful in aiding clinicians in the prediction of these behaviors.

J Clin Psychiatry 2010;71(12):1617-1628
(C) Copyright 2010 Physicians Postgraduate Press, Inc.

Submitted: December 19, 2008; accepted July 10, 2009.

Online ahead of print: August 24, 2010 (doi:10.4088/JCP.08m04967blu). Corresponding author: Ronald C. Kessler, PhD, Department of Health Care Policy, Harvard Medical School, 180 Longwood Ave, Boston, MA 02115 (Kessler@hcp.med.harvard.edu).
A pproximately $9 \%$ of people report having serious thoughts of suicide at some point in their lives, and $3 \%$ actually make a suicide attempt. ${ }^{1,2}$ Although most suicide attempts do not result in death, each attempt carries a chance of serious long-term physical injury, is associated with significant psychological suffering, and increases the likelihood of subsequent suicide attempts and death. ${ }^{3-5}$ As a result, the accurate prediction of suicide attempts is of critical importance to clinicians.

Unfortunately, although many studies have identified risk factors for suicidal behaviors, ${ }^{1,6-10}$ this information has not led to a reduction in the rate of death by suicide or suicidal behaviors. ${ }^{2,11}$ Several obstacles have prevented the translation of these findings into usefulness in clinical settings-a high priority for clinical science. ${ }^{12,13}$ First, most prior studies have used relatively small and selective samples (eg, college students or psychiatric inpatients) and have focused on long-term prediction (5-20 years) rather than short-term risk-raising questions about the generality and clinical utility of the identified risk factors. Second, most studies have identified risk factors for suicidal thoughts or attempts but not what factors predict which suicide ideators will make a suicide attempt. This is an important concern for clinicians who often must predict not who in the general population will make a suicide attempt, but which of their clients with suicidal thoughts will make a suicide attempt in the coming days, weeks, or months. Third, many risk factors identified in prior studies, such as diagnoses obtained from semistructured interviews or the results of extensive self-report questionnaires, ${ }^{6,8,10}$ cannot be feasibly assessed in clinical settings. Fourth, prior studies have identified individual risk factors but have not yielded a method of combining risk factors to derive a single measure of the short-term (eg, 12-month) risk of a suicide attempt. More specifically, prior research has shown that suicide attempts are predicted by specific demographic factors, ${ }^{1,14-16}$ family history factors, ${ }^{17,18}$ childhood adversities, ${ }^{19-21}$ psychiatric disorders, ${ }^{7,822-26}$ and past history of suicidal behaviors. ${ }^{27,28}$ However, this research has not yet provided clinicians with a method of systematically assessing these factors and using the resulting information to estimate the level of risk associated with their presence. 
The primary goals of this study were to identify risk factors for 12-month suicide attempts and to use this information to develop a clinically useful method of predicting suicide attempts that addresses many of the limitations noted in prior work on this problem. Data are from the World Health Organization (WHO) World Mental Health (WMH) Survey Initiative, the size and scope of which provide a unique opportunity to carefully examine this low base-rate behavior. We report here on the 12-month prevalence of suicide ideation, plans, and attempts across these countries and on the risk factors for 12-month suicide attempts among those with suicide ideation. We use a data-driven actuarial approach similar to that used successfully to develop prediction models for violent behavior ${ }^{29-33}$ and most recently to predict 12-month suicide attempts among US respondents. ${ }^{34}$ As in that earlier work, our goal was to develop a risk index that clinicians can use to quickly and easily assess the risk of 12-month suicide attempts. The use of such risk indices has the additional advantage of estimating risk without asking directly about the behavior being predicted-as is done in approaches that rely on the endorsement of critical items-and so can be especially useful when assessing the likelihood of sensitive behaviors such as suicidal thoughts and attempts.

\section{METHOD}

\section{Respondent Samples}

The WMH surveys were carried out in 10 countries classified by the World Bank ${ }^{20}$ as developed (Belgium, France, Germany, Israel, Italy, Japan, Netherlands, New Zealand, Spain, and the United States) and 11 countries classified as developing (Brazil, Bulgaria, Colombia, India, Lebanon, Mexico, Nigeria, the People's Republic of China, Romania, South Africa, and Ukraine) (Table 1). All surveys were conducted face-to-face by trained lay interviewers among multistage household probability samples and were completed between 2001 and 2007. The total sample size was 108,705 , with individual country sample sizes ranging from 2,357 in Romania to 12,790 in New Zealand. The weighted mean response rate across all countries was $73.0 \%$.

\section{Procedures}

All respondents completed a Part I interview that contained core diagnostic assessments, including the assessment of suicidal behaviors. All Part I respondents who met criteria for any disorder and a subsample of approximately $25 \%$ of other respondents were administered a Part II interview that assessed potential correlates and disorders of secondary interest. All respondents in Israel completed Part II. Data were weighted to adjust for differential sampling of Part I respondents into Part II, differential probabilities of selection within households, and to match samples to population socio-demographic distributions.

Standardized interviewer training procedures, WHO translation protocols for all study materials, and quality control procedures for interviewer and data accuracy were used in all WMH countries. These procedures are described in more detail elsewhere. ${ }^{35}$ Informed consent was obtained before beginning interviews in all countries. Procedures for obtaining informed consent and protecting human participants were approved and monitored for compliance by the institutional review boards of the organizations coordinating the surveys in each country.

\section{Measures of Suicidal Behaviors}

Suicidal behaviors were assessed using Version 3.0 of the WMH Composite International Diagnostic Interview (CIDI) ${ }^{36}$ The CIDI contains a module that assesses lifetime occurrence, age at onset, and recency of suicide ideation ("Have you ever seriously thought about committing suicide?"), plans ("Have you ever made a plan for committing suicide?"), and attempts ("Have you ever attempted suicide?"). Respondents who reported any of these experiences in the past 12 months are the focus of the current report. On the basis of evidence that reports of such experiences are higher in self-administered than interviewer-administered surveys, ${ }^{37}$ responses to these questions were obtained in a self-administered booklet.

\section{Risk Factors for Suicidal Behaviors}

We examined 5 sets of possible predictors of suicide attempts among ideators: sociodemographic characteristics, parental psychopathology, childhood adversities, respondent history of past suicidal behaviors, and 12-month respondent Diagnostic and Statistical Manual of Mental Disorders, Fourth Edition $(D S M-I V)^{72}$ mental disorders. Each of these 5 has been found to predict suicide attempts in previous studies. The sociodemographic characteristics module assessed 6 previously documented predictors of suicide attempts: age, gender, education, family income, marital status, and employment. ${ }^{1,14-16}$

The measures of parental psychopathology included the 5 most commonly occurring disorders found in previous research to be associated with a wide range of suicidal behaviors ${ }^{17,18}$ : major depressive episode, panic disorder, generalized anxiety disorder, substance dependence, and antisocial personality disorder. These parent disorders were assessed with respondent reports using the Family History Research Diagnostic Criteria Interview ${ }^{38}$ and its expansion. ${ }^{39}$ We also assessed parent history of attempted and completed suicides.

The childhood adversities included 3 broad classes that have been found to predict suicidal behaviors in previous studies ${ }^{19-21}$ : childhood losses (parental death, parental divorce, and other major losses), indicators of childhood family dysfunction (parental criminal behavior, physical abuse, sexual abuse, family violence, and economic adversity), and respondent serious physical illness. These childhood adversities were assessed with measures developed for the US National Comorbidity Survey. ${ }^{40}$

The measures of past suicidal behaviors, which have consistently been found to predict future suicide attempts, ${ }^{27,28}$ include information about history of ideation, plans, and 


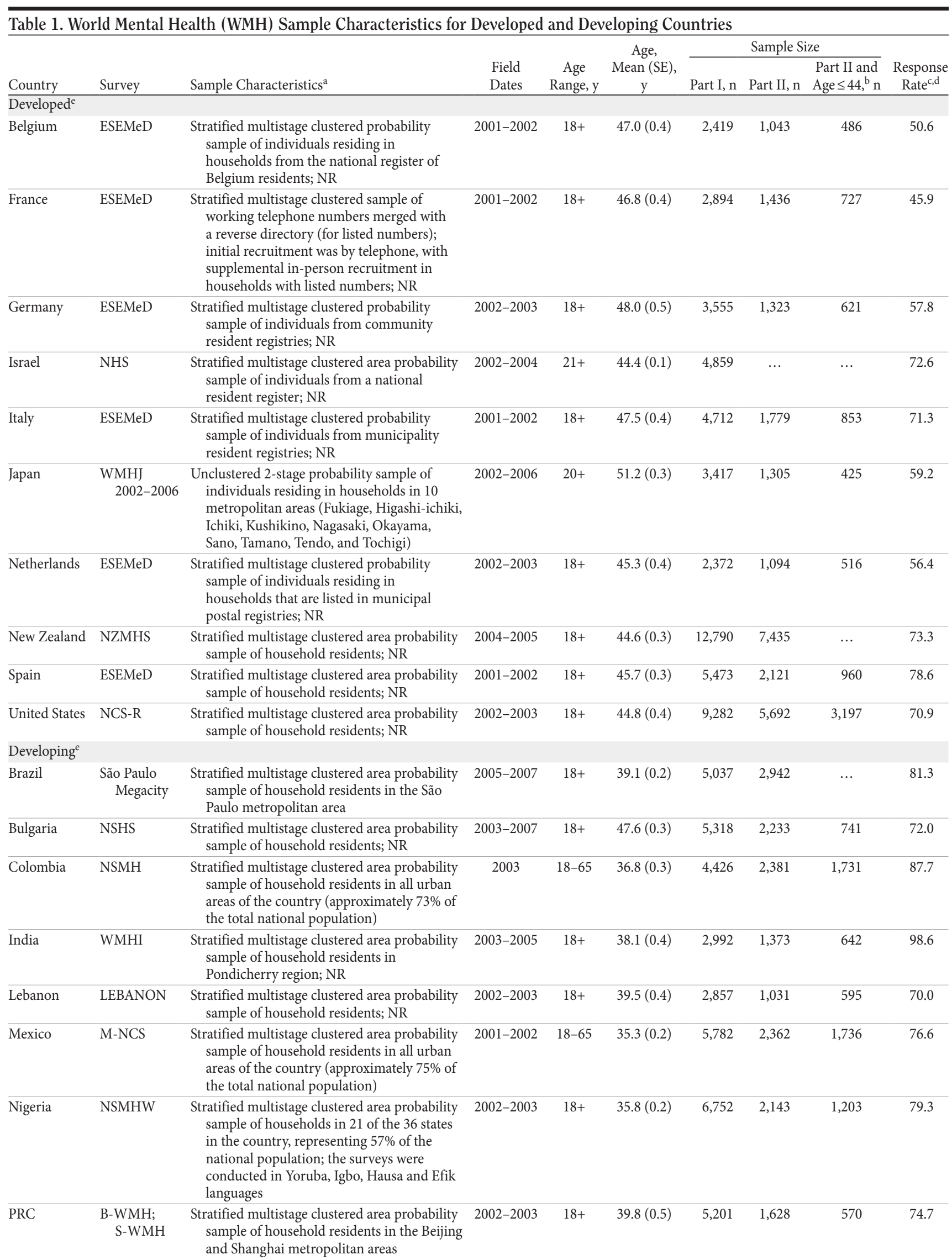




\begin{tabular}{|c|c|c|c|c|c|c|c|c|c|}
\hline \multirow[b]{2}{*}{ Country } & \multirow[b]{2}{*}{ Survey } & \multirow[b]{2}{*}{ Sample Characteristics ${ }^{\mathrm{a}}$} & \multirow[b]{2}{*}{$\begin{array}{l}\text { Field } \\
\text { Dates }\end{array}$} & \multirow[b]{2}{*}{$\begin{array}{c}\text { Age } \\
\text { Range, y }\end{array}$} & \multirow{2}{*}{$\begin{array}{c}\text { Age, } \\
\text { Mean (SE), } \\
y\end{array}$} & \multicolumn{3}{|c|}{ Sample Size } & \multirow[b]{2}{*}{$\begin{array}{c}\text { Response } \\
\text { Rate } \mathrm{c}, \mathrm{d}\end{array}$} \\
\hline & & & & & & Part I, n & Part II, n & $\begin{array}{c}\text { Part II and } \\
\text { Age } \leq 44,{ }^{\mathrm{b}} \mathrm{n}\end{array}$ & \\
\hline PRC & Shenzhen & $\begin{array}{l}\text { Stratified multistage clustered area probability } \\
\text { sample of household residents and } \\
\text { temporary residents in the Shenzhen area }\end{array}$ & $2006-2007$ & $18+$ & $29.4(0.1)$ & 7,134 & 2,476 & 1,993 & 80.0 \\
\hline Romania & RMHS & $\begin{array}{l}\text { Stratified multistage clustered area probability } \\
\text { sample of household residents; NR }\end{array}$ & $2005-2006$ & $18+$ & $45.5(0.5)$ & 2,357 & $\ldots$ & $\ldots$ & 70.9 \\
\hline South Africa & SASH & $\begin{array}{l}\text { Stratified multistage clustered area probability } \\
\text { sample of household residents; NR }\end{array}$ & 2003-2004 & $18+$ & $37.1(0.3)$ & 4,351 & $\ldots$ & $\ldots$ & 87.1 \\
\hline Ukraine & CMDPSD & $\begin{array}{l}\text { Stratified multistage clustered area probability } \\
\text { sample of household residents; NR }\end{array}$ & 2002 & $18+$ & $46.1(0.4)$ & 4,725 & 1,720 & 541 & 78.3 \\
\hline \multicolumn{10}{|c|}{$\begin{array}{l}\text { aMost WMH surveys are based on stratified multistage clustered area probability household samples in which samples of areas equivalent to counties } \\
\text { or municipalities in the United States were selected in the first stage followed by } 1 \text { or more subsequent stages of geographic sampling (eg, towns } \\
\text { within counties, blocks within towns, households within blocks) to arrive at a sample of households, in each of which a listing of household members } \\
\text { was created, and } 1 \text { or } 2 \text { people were selected from this listing to be interviewed. No substitution was allowed when the originally sampled household } \\
\text { resident could not be interviewed. These household samples were selected from Census area data in all countries other than France (where telephone } \\
\text { directories were used to select households) and the Netherlands (where postal registries were used to select households). Several WMH surveys } \\
\text { (Belgium, Germany, Italy) used municipal resident registries to select respondents without listing households. The Japanese sample is the only totally } \\
\text { unclustered sample, with households randomly selected in each of the } 4 \text { sample areas and } 1 \text { random respondent selected in each sample household. } \\
16 \text { of the } 22 \text { surveys are based on NR household samples, while } 2 \text { others are based on nationally representative household samples in urbanized areas } \\
\text { (Colombia, Mexico). } \\
\text { bBrazil, Israel, New Zealand, Romania, and South Africa did not have an age restricted Part II sample. All other countries, with the exception of India, } \\
\text { Nigeria, People's Republic of China, and Ukraine (which were age restricted to } \leq 39 \text { ) were age restricted to } \leq 44 \text {. } \\
\text { 'The response rate is calculated as the ratio of the number of households in which an interview was completed to the number of households originally } \\
\text { sampled, excluding from the denominator households known not to be eligible either because of being vacant at the time of initial contact or because } \\
\text { the residents were unable to speak the designated languages of the survey. }\end{array}$} \\
\hline
\end{tabular}

attempt. Respondent 12-month DSM-IV disorders, finally, were assessed using version 3.0 of the WMH-CIDI, ${ }^{36}$ a fullystructured research diagnostic interview. The assessment included the vast majority of the disorders documented to predict suicide attempts in previous studies, ${ }^{7,8,22-26}$ including anxiety disorders (panic disorder, agoraphobia without a history of panic disorder, generalized anxiety disorder, specific phobia, social phobia, posttraumatic stress disorder, and adult separation anxiety disorder), mood disorders (major depressive disorder, dysthymic disorder, and bipolar disorder), externalizing disorders (adult attention-deficit/ hyperactivity disorder, oppositional-defiant disorder, conduct disorder, and intermittent explosive disorder), and substance disorders (alcohol and illegal drug abuse and dependence). Clinical reappraisal studies carried out in conjunction with a number of WMH surveys documented generally good concordance between DSM-IV diagnoses based on the CIDI and diagnoses based on blinded clinical reappraisal interviews with the Structured Clinical Interview for $D S M-I V^{41}$ in probability subsamples of WMH respondents. ${ }^{42}$ Organic exclusion rules and diagnostic hierarchy rules were used in making all respondent diagnoses.

\section{Statistical Analyses}

We examined 12-month prevalence of ideation, plans, and attempts using cross-tabulations. We then estimated the associations between hypothesized correlates of suicide ideation and, among ideators, planned and unplanned suicide attempts using bivariate and multivariate logistic regression analysis. ${ }^{43}$ Logistic regression coefficients and $95 \%$ CIs were converted to odds ratios (ORs) for ease of interpretation. Continuous variables were divided into categories to minimize effects of extreme values. Categories were collapsed to stabilize associations when ORs did not differ meaningfully. Standard errors and significance tests were estimated with the Taylor series method ${ }^{44}$ using SUDAAN software ${ }^{45}$ to adjust for design effects. Multivariate significance was evaluated with Wald $\chi^{2}$ tests based on design-corrected coefficient variance-covariance matrices. Statistical significance was evaluated with 2 -tailed, .05-level tests.

After identifying significant risk factors, a summary risk index was constructed for planned and unplanned suicide attempts separately for developed and developing countries (see eAppendix 1). We began by combining the predictors that had ORs over 2.0 or under 0.5 in the earlier bivariate models into new multivariate models. These models included statistical controls for country, age, and age squared in order to ensure that effects were not explained by these factors. The predictors that continued to have ORs above 2.0 or below 0.5 in the multivariate models were used to create the index by constructing a predicted probability of the outcome from a version of the multivariate model that contained only these predictors. This distribution of predicted probabilities was then inspected and divided into risk strata using the 
logic of stratum-specific likelihood ratios, ${ }^{46}$ ie, we divided the distribution into strata large enough to find statistically significant monotonic relationships between all contiguous pairs of strata. Three measures of screening scale performance were then calculated for each stratum: positive predictive value (the proportion of the respondents in the stratum who made an attempt), sensitivity, (the proportion of all attempters who were in the stratum), and specificity, (the proportion of all nonattempters who were in the stratum). We also calculated area under the receiver operating characteristic curve (AUC), ${ }^{47}$ a summary measure of prediction accuracy that, unlike the more familiar Cohen's $\kappa,{ }^{48}$ is not influenced by marginal distributions. ${ }^{49}$

\section{RESULTS}

\section{Prevalence}

Each type of suicidal behavior assessed occurred at a slightly higher rate in developing than in developed countries. More specifically, estimates of the 12-month prevalence of suicide ideation, plans, and attempts were $2.0 \%, 0.6 \%$, and $0.3 \%$, respectively, for developed countries and $2.1 \%$, $0.7 \%$, and $0.4 \%$ for developing countries (Table 2). Overall, roughly one-third of 12-month ideators developed a suicide plan, and this proportion was significantly higher in developing than developed countries $\left(34.1 \%\right.$ vs $28.9 \%, \chi^{2}{ }_{1}=4.6$, $P=.032$ ). A slightly lower percentage of 12 -month ideators made a suicide attempt, and this proportion was also higher in developing than developed countries $(20.2 \%$ vs $15.1 \%$, $\left.\chi_{1}^{2}=6.1, P=.001\right)$. Developing countries also had a higher prevalence of attempts among ideators with a suicide plan $\left(41.8 \%\right.$ vs $\left.32.6 \%, \chi^{2}{ }_{1}=4.0, P=.046\right)$ and a nonsignificantly higher prevalence of attempts among ideators without a plan (9.0\% vs $\left.8.0 \%, \chi^{2}{ }_{1}=0.3, P=.59\right)$. Despite this low rate of unplanned suicide attempts, it is important to note that unplanned (presumably impulsive) attempts constituted $37.7 \%$ of all attempts in developed countries and $29.4 \%$ in developing countries.

\section{Risk Factors for}

\section{2-Month Suicide Attempts Among Ideators}

Suicide ideation was significantly more prevalent among women than men in both developed $\left(2.2 \%\right.$ vs $1.7 \%, \chi_{1}{ }_{1}=12.5$, $P<.001)$ and developing $\left(2.4 \%\right.$ vs $\left.1.6 \%, \chi^{2}{ }_{1}=25.1, P<.001\right)$ countries. Suicide plans were significantly more common among women than men in developing $(0.8 \%$ vs $0.6 \%$, $\chi_{1}^{2}=7.0, P=.008$ ), but not developed, countries. Gender differences in the prevalence of attempts were not significant in either developed or developing countries. Overall, few sociodemographic variables were associated with suicide attempts among ideators. Specifically, in developed countries, younger age (ie, $<50$ years old) predicted unplanned attempts among ideators and unemployment predicted planned attempts. In developing countries, being a student predicted unplanned attempts and unemployment again predicted planned attempts. The bivariate ORs of these significant predictors were in the range 2.4-9.4 (detailed results are not reported, but are available on request).

Parental psychopathology and other childhood family adversities were found to be consistently significant predictors of 12-month suicide ideation in both developed and developing countries, with ORs in the range 1.6-4.8 (median $=2.7$; interquartile range, 2.1-3.1) (detailed results are not presented but are available on request). However, few of these measures significantly predicted either planned or unplanned suicide attempts among ideators (Table 3). In developed countries, childhood physical abuse predicted both planned and unplanned attempts, whereas sexual abuse predicted only planned suicide attempts, and childhood neglect and family violence predicted unplanned attempts. In developing countries, none of the 16 parental psychopathologies or childhood adversities considered in the analysis predicted planned attempts, while parental generalized anxiety disorder was the only significant predictor of unplanned attempts. The bivariate ORs of these significant predictors were in the range 2.3-4.4.

Respondent 12-month DSM-IV disorders were strong predictors of 12-month suicide ideation in both developed and developing countries. Virtually all of the 16 disorders considered were significant predictors of ideation, with ORs in the range 3.3-15.3 (median $=7.1$; interquartile range, 4.9-9.1). (Detailed results are not presented but are available on request.) However, few of these disorders significantly predicted suicide attempts among ideators (Table 4). In developed countries, specific phobia $(\mathrm{OR}=2.6)$ and conduct disorder $(\mathrm{OR}=16.4)$ were the only disorders that predicted 
Table 3. Bivariate Associations of Parental Psychopathology and Other Childhood Family Adversities With 12-Month Suicide Attempts Among 12-Month Ideators in the World Mental Health Surveys ${ }^{\mathrm{a}}$

\begin{tabular}{|c|c|c|c|c|c|c|c|c|c|c|c|c|c|c|c|c|}
\hline \multirow[b]{3}{*}{ Adversity } & \multicolumn{8}{|c|}{ Developed Countries } & \multicolumn{8}{|c|}{ Developing Countries } \\
\hline & \multicolumn{4}{|c|}{ Planned Attempt } & \multicolumn{4}{|c|}{ Unplanned Attempt } & \multicolumn{4}{|c|}{ Planned Attempt } & \multicolumn{4}{|c|}{ Unplanned Attempt } \\
\hline & $\mathrm{n}$ & $\%(\mathrm{SE})$ & OR & $(95 \% \mathrm{CI})$ & $\mathrm{n}$ & $\%(\mathrm{SE})$ & OR & $(95 \% \mathrm{CI})$ & $\mathrm{n}$ & $\%(\mathrm{SE})$ & OR & $(95 \% \mathrm{CI})$ & $\mathrm{n}$ & $\%(\mathrm{SE})$ & OR & $\overline{(95 \% \mathrm{CI})}$ \\
\hline \multicolumn{17}{|c|}{ Parental psychopathology } \\
\hline Parent suicide & 15 & $7.2(1.9)$ & 0.4 & $(0.1-2.0)$ & 30 & $6.4(1.4)$ & 0.9 & $.1-6.9)$ & 31 & $7.5(1.5)$ & 1.3 & $(0.4-3.9)$ & 30 & $3.5(0.8)$ & 0.7 & $(0.1-3.2)$ \\
\hline $\begin{array}{l}\text { Parent } \\
\quad \text { depression }\end{array}$ & 23 & $6.7(1.6)$ & 2.1 & $(0.7-6.5)$ & 26 & $3.5(0.9)$ & 0.5 & $(0.1-2.2)$ & 27 & $5.8(1.2)$ & 1.0 & $(0.4-2.4)$ & 31 & $4.5(1.1)$ & 2.8 & $(0.9-9.1)$ \\
\hline Parent panic & 18 & $6.0(1.4)$ & 2.9 & $(0.8-10.0)$ & 40 & $5.6(1.1)$ & 1.3 & $(0.3-5.3)$ & 73 & $18.7(2.3)$ & 1.5 & $(0.7-3.3)$ & 73 & $8.8(1.3)$ & 1.5 & $(0.5-4.4)$ \\
\hline Parent GAD & 20 & $6.4(1.5)$ & 1.4 & $(0.4-4.8)$ & 31 & $4.2(0.9)$ & 1.1 & $(0.3-3.6)$ & 31 & $6.5(1.3)$ & 1.1 & $(0.3-3.5)$ & 36 & $5.3(1.2)$ & $3.5^{*}$ & $(1.1-11.4)$ \\
\hline $\begin{array}{l}\text { Parent substance } \\
\text { abuse }\end{array}$ & 17 & $5.9(1.5)$ & 0.6 & $(0.2-2.1)$ & 40 & $4.9(0.8)$ & 2.1 & $(0.8-5.6)$ & 59 & $13.1(1.7)$ & 0.9 & $(0.4-1.7)$ & 86 & $9.7(1.2)$ & 0.5 & $(0.2-1.3)$ \\
\hline Parent ASP & 11 & $3.5(1.1)$ & 2.5 & $(0.7-9.6)$ & 28 & $3.7(0.7)$ & 1.5 & $(0.6-3.6)$ & 27 & $6.3(1.4)$ & 1.0 & $(0.4-2.7)$ & 45 & $5.6(1.0)$ & 0.5 & $(0.1-2.1)$ \\
\hline \multicolumn{17}{|c|}{ Other childhood family adversities } \\
\hline Parent death & 20 & $6.0(1.4)$ & 0.8 & $(0.2-2.6)$ & 49 & $6.1(0.9)$ & 1.5 & $(0.4-$ & 82 & $17.8(2.2)$ & 1.3 & $(0.7-2.3)$ & 109 & $13.4(1.6)$ & 0.6 & $(0.2-2.1)$ \\
\hline Parent divorce & 19 & $9.3(2.3)$ & 2.7 & $(0.9-7.6)$ & 60 & $10.1(1.3)$ & 0.8 & $(0.3-2.2)$ & 29 & $6.3(1.3)$ & 1.2 & $(0.4-3.2)$ & 48 & $5.9(1.0)$ & 0.3 & $(0.1-1.8)$ \\
\hline $\begin{array}{l}\text { Other parent } \\
\text { loss }\end{array}$ & 17 & $5.1(1.3)$ & 0.4 & $(0.1-1.5)$ & 37 & $5.1(1.0)$ & 2.2 & $(0.5-8.9)$ & 45 & $11.1(1.8)$ & 1.0 & $(0.3-2.9)$ & 75 & $8.8(1.2)$ & 0.3 & $(0.1-1.5)$ \\
\hline Parent criminal & 11 & $4.3(1.4)$ & 3.8 & $(0.8-18.6)$ & 34 & $4.9(0.7)$ & 2.7 & $(0.7-10.0)$ & 26 & $6.2(1.4)$ & 0.9 & $(0.3-2.5)$ & 42 & $6.2(1.0)$ & 1.4 & $(0.3-5.5)$ \\
\hline Physical abuse & 101 & $27.9(3.2)$ & $2.3^{*}$ & $(1.2-4.5)$ & 150 & $19.2(1.8)$ & $2.8^{*}$ & $(1.4-5.6)$ & 125 & $28.7(2.4)$ & 1.1 & $(0.6-2.1)$ & 169 & $19.8(2.1)$ & 1.0 & $(0.5-1.9)$ \\
\hline Sexual abuse & 67 & $18.6(2.6)$ & $2.3^{*}$ & $(1.1-4.7)$ & 102 & $12.0(1.5)$ & 2.2 & $(0.8-6.0)$ & 18 & $3.3(0.9)$ & 1.6 & $(0.4-6.8)$ & 22 & $2.7(0.7)$ & 1.8 & $(0.5-6.6)$ \\
\hline Neglect & 23 & $8.9(1.9)$ & 2.0 & $(0.8-5.0)$ & 23 & $3.4(0.7)$ & $4.4^{*}$ & $(1.1-17.3)$ & 48 & $12.5(2.1)$ & 0.8 & $(0.3-1.9)$ & 70 & $8.0(1.2)$ & 1.2 & $(0.4-3.8)$ \\
\hline Physical illness & 25 & $7.3(1.7)$ & 1.8 & $(0.7-4.5)$ & 53 & $6.4(1.0)$ & 1.8 & $(0.8-4.4)$ & 22 & $5.7(1.2)$ & 1.4 & $(0.4-4.6)$ & 32 & $4.5(1.0)$ & 2.1 & $(0.5-8.6)$ \\
\hline Family violence & 90 & $24.3(3.0)$ & 2.0 & $(0.9-4.0)$ & 148 & $17.2(1.6)$ & $3.6^{*}$ & $(1.9-7.0)$ & 73 & $17.1(2.0)$ & 1.4 & $(0.7-2.6)$ & 100 & $11.1(1.4)$ & 1.0 & $(0.3-3.0)$ \\
\hline Economic & 20 & $8.8(2.3)$ & 1.6 & $(0.6-4.7)$ & 35 & $4.9(0.9)$ & 2.3 & $(0.6-9.1)$ & 16 & $4.3(1.4)$ & 0.4 & $(0.1-1.3)$ & 24 & $2.7(0.6)$ & 0.5 & $(0.1-4.8)$ \\
\hline
\end{tabular}

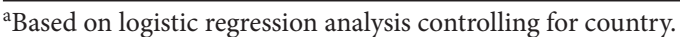

* Significant at the .05 level, 2-sided test.

Abbreviations: ASP = antisocial personality, GAD = generalized anxiety disorder.

planned suicide attempts, while none predicted unplanned attempts. In developing countries, panic disorder $(\mathrm{OR}=3.9)$, conduct disorder $(\mathrm{OR}=10.0)$, and drug abuse/dependence $(\mathrm{OR}=7.3)$ were the only disorders that predicted planned attempts positively. Generalized anxiety disorder was associated with a significantly reduced risk of making a planned attempt $(\mathrm{OR}=0.3)$. Adult separation anxiety disorder was the only disorder the predicted unplanned attempts positively $(\mathrm{OR}=4.0)$, while generalized anxiety disorder was associated with a significantly reduced risk of making an unplanned attempt $(\mathrm{OR}=0.0)$. The bivariate $\mathrm{ORs}$ of the significant positive predictors were in the range 2.6-16.4, although it should be noted that the CIs for the higher ORs were quite wide because of the comparative rarity of the predictor disorders.

History of prior suicidality was significantly associated with highly elevated odds of 12-month suicide ideation in both developed and developing countries, with bivariate ORs in the range 28.4-48.2. (Detailed results are not presented, but are available on request.) However, the ORs were less extreme and also more varied in predicting suicide attempts among ideators (Table 5). Three results are noteworthy: First, 12-month ideators with a past history of ideation in the absence of a lifetime plan or attempt were significantly less likely to make a first attempt in the 12 months before interview than were 12 -month ideators with no prior history of suicide ideation. This pattern was found both in developed and developing countries, with ORs in the range $0.1-0.2$. Similarly, 12 -month ideators with a prior history of a suicide plan but no prior attempt were significantly less likely to make a planned attempt in the 12 months before the interview than were 12-month ideators with no prior plan. Second, 12-month ideators with a history of prior unplanned (ie, impulsive) attempts in both developed and developing countries had significantly elevated odds of an unplanned attempt (ORs=6.2-9.3) but not a planned attempt $(\mathrm{ORs}=1.3-2.7)$ than those with no prior history. Third, 12-month ideators with a history of prior planned attempts had modestly elevated odds of planned attempts in developed countries $(\mathrm{OR}=1.8)$ and of both planned and unplanned attempts in developing countries (ORs $=1.7-$ 1.8), although none of these associations was statistically significant. Taken together, these findings indicate that the presence of prior ideation and plans in the absence of a suicide attempt are associated with decreased likelihood of acting on suicide ideation in the prior 12 months; whereas the presence of a prior suicide attempt is associated with increased odds of acting on suicide ideation in the prior 12 months-with evidence of specificity such that those with unplanned attempts have higher odds of subsequent unplanned attempts and those with planned attempts have higher odds of subsequent planned attempts.

\section{Summary Risk Index for \\ 12-Month Suicide Attempt Among Ideators}

The summary risk indices, which are made up of the significant predictors from multivariate versions of the foregoing equations, have AUCs in the range of 74.0-79.7 across the 4 outcomes (ie, planned and unplanned attempts in both developed and developing countries; Table 6). This means that a randomly selected suicide attempter could be distinguished from a randomly selected nonattempter with 
Table 4. Bivariate Associations of 12-Month DSM-IV/CIDI Disorders With 12-Month Suicide Attempts Among 12-Month Ideators in the World Mental Health Surveys ${ }^{\mathrm{a}}$

\begin{tabular}{|c|c|c|c|c|c|c|c|c|c|c|c|c|c|c|c|c|}
\hline \multirow[b]{3}{*}{ Disorder } & \multicolumn{8}{|c|}{ Developed Countries } & \multicolumn{8}{|c|}{ Developing Countries } \\
\hline & \multicolumn{4}{|c|}{ Planned Attempt } & \multicolumn{4}{|c|}{ Unplanned Attempt } & \multicolumn{4}{|c|}{ Planned Attempt } & \multicolumn{4}{|c|}{ Unplanned Attempt } \\
\hline & $\mathrm{n}$ & $\%(\mathrm{SE})$ & OR & $(95 \%$ & $\mathrm{n}$ & $\%(\mathrm{SE})$ & OR & $(95 \% \mathrm{CI})$ & $\mathrm{n}$ & $\%(\mathrm{SE})$ & OR & $(95 \%$ & $\mathrm{n}$ & $\%(\mathrm{SE})$ & OR & $(95 \% \mathrm{CI})$ \\
\hline \multicolumn{17}{|l|}{ Anxiety disorders } \\
\hline Panic disorder & 65 & $18.5(2.3)$ & 1.8 & $(0.9-3$ & 68 & $9.7(1.6)$ & 1.3 & $(0.6-3.1)$ & 22 & $5.4(1.3)$ & $3.9^{*}$ & $(1.4-11.3)$ & 28 & $3.1(0.7)$ & $\ldots^{b}$ & $\mathrm{~b}$ \\
\hline $\begin{array}{l}\text { Agoraphobia } \\
\text { without panic }\end{array}$ & 16 & $4.9(1.4)$ & 1.2 & $(0.4-4.0)$ & 30 & $4.1(0.9)$ & 0.3 & $(0.0-1.9)$ & 35 & $7.0(1.4)$ & 1.1 & $(0.5$ & 29 & $2.8(0.6)$ & 1.2 & $(0.3-4.2)$ \\
\hline $\begin{array}{l}\text { Generalized anxiety } \\
\text { disorder }\end{array}$ & 38 & $13.0(2.5)$ & 1.1 & $(0.5-2.6)$ & 91 & $11.8(1.4)$ & 0.6 & $(0.2-1.6)$ & 24 & $5.6(1.3)$ & $0.3^{*}$ & $(0.1-0.9)$ & 34 & $4.1(1.0)$ & $0.0^{*}$ & $(0.0-0.0)^{*}$ \\
\hline Specific phobia & 87 & $30.8(3.6)$ & $2.6^{*}$ & $(1.4-5.0)$ & 144 & $20.2(1.7)$ & 1.0 & $(0.5-2.0)$ & 78 & $23.5(2.5)$ & 0.8 & $(0.4-1.6)$ & 116 & $16.3(1.7)$ & 1.0 & $(0.4-2.7)$ \\
\hline ocial phobia & 91 & $33.7(3.4)$ & 0.9 & $(0.5-1.7)$ & 139 & $20.6(1.9)$ & 1.4 & $(0.6-3.1)$ & 40 & $9.5(1.9)$ & 0.9 & $(0.4-2.1)$ & 52 & $6.5(1.1)$ & 0.8 & $(0.3-2.0)$ \\
\hline $\begin{array}{l}\text { Posttraumatic stress } \\
\text { disorder }\end{array}$ & 67 & $17.4(2.3)$ & 1.6 & $(0.8-3.2)$ & 98 & $13.9(1.8)$ & 1.1 & $(0.5-2.7)$ & 20 & $4.4(0.9)$ & 1.7 & $(0.4-7.4)$ & 24 & $3.5(0.8)$ & 0.3 & $(0.1-1.3)$ \\
\hline $\begin{array}{l}\text { Adult separation } \\
\text { anxiety disorder }\end{array}$ & 14 & $13.3(4.0)$ & 1.2 & $(0.3-4.6)$ & 29 & $8.9(1.5)$ & 1.4 & $(0.4-5.0)$ & 29 & $10.2(2.0)$ & 1.2 & $(0.4-3.1)$ & 28 & $5.6(1.5)$ & $4.0^{*}$ & $(1.1-15.0)$ \\
\hline $\begin{array}{l}\text { Any anxiety } \\
\text { disorder }\end{array}$ & 204 & $63.4(3.3)$ & 1.8 & $(0.9-3.7)$ & 347 & $45.8(2.2)$ & 1.4 & $(0.7-2.7)$ & 158 & $37.0(2.7)$ & 1.4 & $(0.8-2.4)$ & 228 & $29.2(2.0)$ & 1.1 & $(0.6-2.4)$ \\
\hline \multicolumn{17}{|l|}{ Mood disorders } \\
\hline $\begin{array}{l}\text { Major depressive } \\
\text { disorder }\end{array}$ & 150 & $50.0(3.3)$ & 0.9 & $(0.5$ & 253 & $34.1(2.1)$ & 1.6 & $(0.9-2.7)$ & 157 & $33.3(2.6)$ & 1.1 & $(0.6$ & 191 & $25.2(1.9)$ & 1.6 & $(0.8-3.5)$ \\
\hline ysthymic disorder & 28 & $.3(2.8)$ & 1.1 & $(0.3-$ & 43 & $5.4(1.0)$ & 0.3 & $(0.1$ & 21 & $5.2(1.1)$ & 1.0 & $(0.3$ & 18 & $2.3(0.6)$ & 2.2 & $(0.6-8.3)$ \\
\hline olar disorder & 50 & $17.7(2.5)$ & 1.5 & $(0.8-$ & 68 & 12.8 & 0.9 & & 29 & 12.4 & 0.7 & & 28 & $4.1(1.0)$ & 0.8 & $(0.2-2.9)$ \\
\hline Any mood disorder & 203 & $63.0(3.3)$ & 1.1 & $(0.6-2.0)$ & 325 & $43.8(2.3)$ & 1.5 & $(0.9-2.6)$ & 176 & $38.1(2.7)$ & 1.1 & $(0.7-1.9)$ & 214 & $27.5(1.9)$ & 1.6 & $(0.8-3.4)$ \\
\hline \multicolumn{17}{|c|}{ Externalizing disorders } \\
\hline $\begin{array}{l}\text { Attention-deficit/ } \\
\text { hyperactivity } \\
\text { disorder }\end{array}$ & 15 & $10.7(2.9)$ & 1.3 & $(0.4-4.8)$ & 16 & $5.4(1.6)$ & 1.2 & $(0.3-5.2)$ & 6 & $1.8(0.8)$ & 0.2 & $(0.0$ & 4 & $0.6(0.3)$ & $\ldots^{b}$ & $\ldots^{b}$ \\
\hline $\begin{array}{l}\text { Oppositional- } \\
\text { defiant disorder }\end{array}$ & 8 & $8.2(2.8)$ & 1.5 & $(0.3-6.7)$ & 9 & $3.2(1.2)$ & 4.8 & $(0.9-25.2)$ & 3 & $3.2(2.4)$ & 3.0 & $(0.3-30.5)$ & 4 & $1.3(0.7)$ & $\ldots^{\mathrm{b}}$ & $\ldots^{\mathrm{b}}$ \\
\hline Conduct disorder & 4 & $2.4(1.4)$ & $16.4^{*}$ & $(1.0-265.1)$ & 4 & $1.1(0.6)$ & 8.7 & $(0.8$ & 6 & $2.1(0.6)$ & $10.0^{*}$ & $(1$. & 4 & $0.4)$ & 3.2 & $(0.4-23.5)$ \\
\hline $\begin{array}{l}\text { Intermittent } \\
\text { explosive disorder }\end{array}$ & 17 & $19.1(4.1)$ & 1.1 & $(0.3-4.0)$ & 27 & $11.1(2.3)$ & 0.6 & $(0.1-3.3)$ & 47 & $13.6(2.1)$ & 1.3 & $(0.6-2.6)$ & 60 & $8.5(1.3)$ & 2.3 & $(0.8-6.4)$ \\
\hline $\begin{array}{l}\text { Any impulse- } \\
\text { control disorder }\end{array}$ & 34 & $22.9(3.5)$ & 1.3 & $(0.5-3.5)$ & 44 & $12.7(2.0)$ & 1.3 & $(0.4-3.9)$ & 55 & $14.4(2.0)$ & 1.3 & $(0.6-2.8)$ & 68 & $8.5(1.2)$ & 1.6 & $(0.7-3.8)$ \\
\hline \multicolumn{17}{|c|}{ Substance use disorders } \\
\hline $\begin{array}{c}\text { Alcohol abuse or } \\
\text { dependence }\end{array}$ & 55 & $18.9(2.6)$ & 1.3 & $(0.6-2.7)$ & 63 & $8.9(1.2)$ & 1.0 & $(0.3-2.8)$ & 44 & $13.1(2.6)$ & 2.0 & $(0.9-4.4)$ & 52 & $7.8(1.2)$ & 0.3 & $(0.1-1.6)$ \\
\hline $\begin{array}{l}\text { Illicit drug abuse or } \\
\text { dependence }\end{array}$ & 38 & $13.8(2.8)$ & 2.5 & $(0.8-7.7)$ & 38 & $5.7(1.1)$ & 2.0 & $(0.7-5.9)$ & 18 & $4.3(1.2)$ & $7.3^{*}$ & $(1.9-28.2)$ & 19 & $3.5(0.8)$ & $\ldots^{\mathrm{b}}$ & $\ldots{ }^{b}$ \\
\hline $\begin{array}{l}\text { Any substance use } \\
\text { disorder }\end{array}$ & 71 & $25.1(3.1)$ & 1.9 & $(0.8-4.5)$ & 84 & $12.2(1.4)$ & 1.4 & $(0.6-3.4)$ & 54 & $15.5(2.7)$ & $2.6^{*}$ & $(1.2-5.8)$ & 62 & $9.6(1.3)$ & 0.3 & $(0.1-1.2)$ \\
\hline \multicolumn{17}{|l|}{ Number of disorders } \\
\hline Any & 266 & $80.7(2.6)$ & 1.3 & $(0.5-2.9)$ & 490 & $65.8(2.1)$ & 1.2 & $(0.6-2.6)$ & 280 & $65.8(2.9)$ & $2.2^{*}$ & $(1.1-4.4)$ & 384 & $49.1(2.2)$ & 1.7 & $(0.8-3.7)$ \\
\hline Exactly one $e^{c}$ & 66 & $16.8(2.4)$ & 0.6 & $(0.2-1.8)$ & 186 & $24.4(1.9)$ & 1.0 & $(0.4-2.6)$ & 128 & $29.0(2.5)$ & $2.1^{*}$ & $(1.0-4.6)$ & 205 & $25.5(2.1)$ & 1.9 & $(0.8-4.6)$ \\
\hline Exactly two ${ }^{c}$ & 69 & $21.3(2.7)$ & 1.7 & $(0.6-4.6)$ & 131 & $18.7(1.7)$ & 1.1 & $(0.4-3.0)$ & 75 & $19.1(2.3)$ & $3.2^{*}$ & $(1.4-7.2)$ & 95 & $13.2(1.7)$ & 1.5 & $(0.5-4.6)$ \\
\hline Three or more ${ }^{c}$ & 131 & $42.5(3.3)$ & 1.6 & $(0.6-4.0)$ & 173 & $22.8(2.1)$ & 1.5 & $(0.6-3.6)$ & 77 & $17.7(2.2)$ & 1.3 & $(0.6-3.0)$ & 84 & $10.5(1.2)$ & 1.7 & $(0.6-5.1)$ \\
\hline \multicolumn{17}{|c|}{$\begin{array}{l}\text { aBsed on logistic regression analysis controlling for country. } \\
\text { b } \leq 1 \text { case with the outcome (planned or unplanned attempt). } \\
\text { cRows based on multivariate regression analysis controlling for country (no disorder is the reference category). } \\
\text { * Significant at the .05 level, } 2 \text {-sided test. } \\
\text { Abbreviations: CIDI = World Health Organization Composite International Diagnostic Interview; DSM-IV=Diagnostic and Statistical Manual of Mental } \\
\text { Disorders, Fourth Edition. }\end{array}$} \\
\hline
\end{tabular}

Table 5. Multivariate Association Between Respondent History of Suicidality and 12-Month Suicide Attempts Among 12-Month Ideators in the World Mental Health Surveys ${ }^{\mathrm{a}}$

\begin{tabular}{|c|c|c|c|c|c|c|c|c|c|c|c|c|c|c|c|c|}
\hline \multirow[b]{3}{*}{ History of Suicidality } & \multicolumn{8}{|c|}{ Developed Countries } & \multicolumn{8}{|c|}{ Developing Countries } \\
\hline & \multicolumn{4}{|c|}{ Planned Attempt } & \multicolumn{4}{|c|}{ Unplanned Attempt } & \multicolumn{4}{|c|}{ Planned Attempt } & \multicolumn{4}{|c|}{ Unplanned Attempt } \\
\hline & $\mathrm{n}$ & $\%(\mathrm{SE})$ & OR & $95 \% \mathrm{CI}$ & $\mathrm{n}$ & $\%(\mathrm{SE})$ & OR & $95 \% \mathrm{CI}$ & $\mathrm{n}$ & $\%(\mathrm{SE})$ & OR & $95 \% \mathrm{CI}$ & $\mathrm{n}$ & $\%(\mathrm{SE})$ & OR & $95 \% \mathrm{CI}$ \\
\hline Ideation only & 15 & $7.2(2.3)$ & $0.1^{*}$ & $0.0-0.6$ & 372 & $50.5(2.3)$ & $0.2^{*}$ & $0.1-0.6$ & 33 & $8.1(1.6)$ & $0.2^{*}$ & $0.1-0.6$ & 338 & $43.4(2.2)$ & 0.6 & $0.3-1.5$ \\
\hline Ideation and plan only & 29 & $8.9(2.0)$ & $0.1^{*}$ & $0.1-0.3$ & 79 & $10.1(1.3)$ & 3.0 & $1.0-9.3$ & 33 & $7.4(1.5)$ & $0.2^{*}$ & $0.1-0.4$ & 78 & $9.4(1.4)$ & 0.5 & $0.1-3.4$ \\
\hline $\begin{array}{l}\text { Ideation and unplanned } \\
\text { attempt }\end{array}$ & 112 & $36.3(3.2)$ & 1.3 & $0.5-3.5$ & 61 & $7.3(1.0)$ & $6.2^{*}$ & $2.6-14.6$ & 89 & $20.9(2.5)$ & 2.7 & $1.0-7.2$ & 54 & $6.0(1.0)$ & $9.3^{*}$ & $4.2-21.0$ \\
\hline $\begin{array}{l}\text { Ideation and planned } \\
\text { attempt }\end{array}$ & 137 & $39.4(3.3)$ & 1.8 & $0.8-3.7$ & 82 & $11.6(1.6)$ & 0.8 & $0.2-2.8$ & 133 & $32.7(3.1)$ & 1.8 & $1.0-3.2$ & 71 & $8.6(1.1)$ & 1.7 & $0.5-5.9$ \\
\hline $\begin{array}{l}\text { No history of ideation, } \\
\text { plan, or attempt }\end{array}$ & $\ldots$ & $\ldots$ & 1.0 & $\ldots$ & $\cdots$ & $\cdots$ & 1.0 & $\cdots$ & $\cdots$ & $\cdots$ & 1.0 & $\cdots$ & $\cdots$ & $\cdots$ & 1.0 & $\cdots$ \\
\hline
\end{tabular}

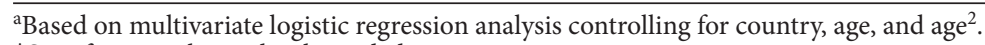

*Significant at the .05 level, 2-sided test. 


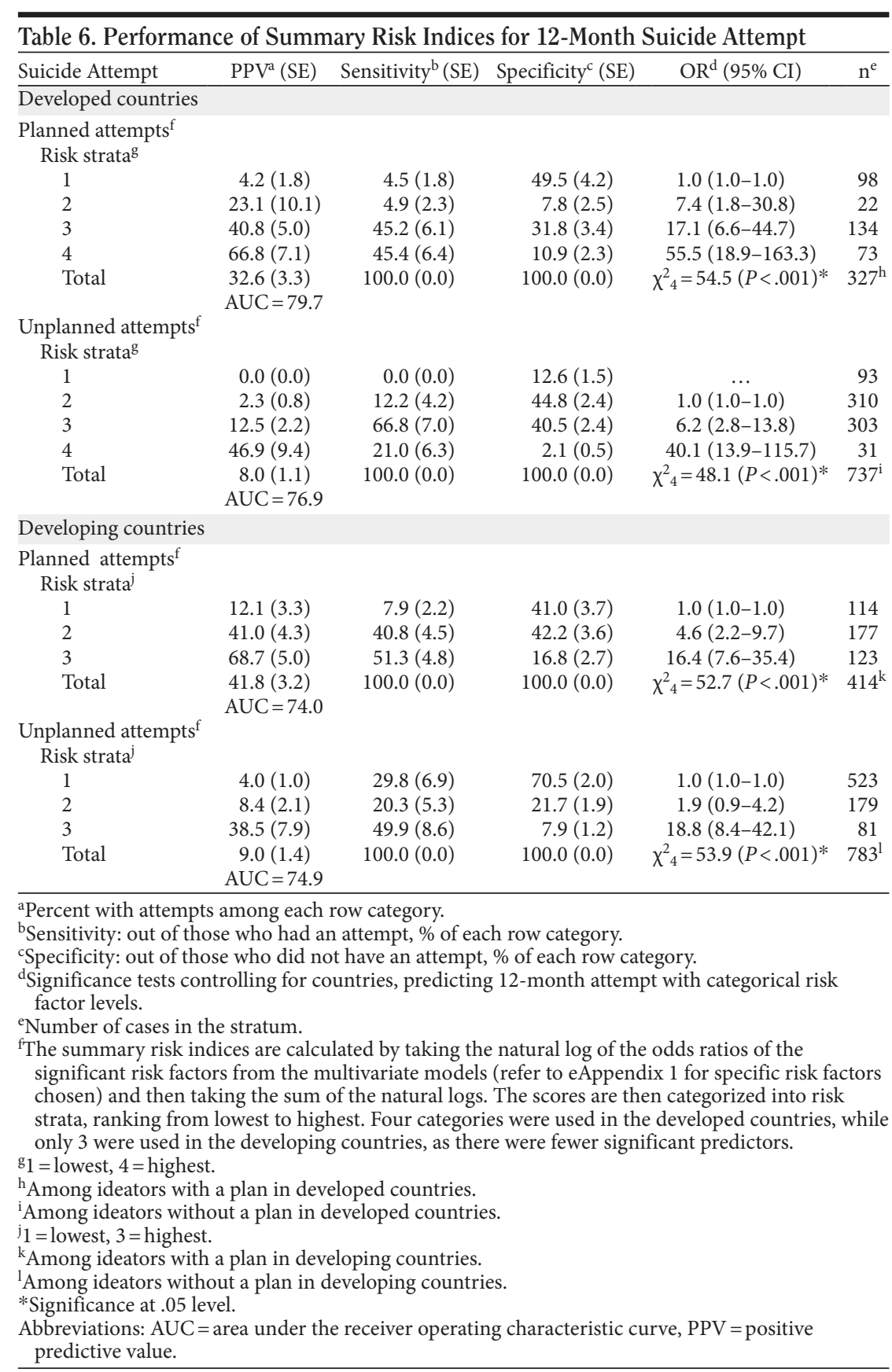

respondents classified as having highest risk than the indices for planned attempts $(3.6 \%-11.6 \%)$, lower proportions of attempts made by people classified at highest risk (21.0\%-49.9\%), and smaller proportions of respondents classified at highest risk who made attempts (38.5\%-46.9\%). (Final versions of each risk index are available on request.)

Even with a dataset as large as the one used here, the low 12-month prevalence of suicide attempts made it impossible to develop stable risk indices separately for each participating country. However, in order to get a rough indication of the performance of the summary risk indices in particular countries, we calculated AUCs to assess concordance between predicted probability of an attempt and actual attempts. The predicted probability estimates were generated from separate equations for planned and unplanned attempts in developed and developing countries. Borrowing standard verbal descriptors used to characterize the strength of $\kappa,^{50}$ the AUC estimates were substantial $(>0.80)$ for nearly $30 \%$ of the replications, moderate $(>0.70-0.80)$ for an additional $25 \%$ of replications, and fair for another $25 \%$. Prediction accuracy was considerably greater, though, in developed countries (nearly 50\% substantial and 70\% either moderate or substantial) than developing countries (less than $20 \%$ substantial and $40 \%$ either moderate or substantial) and somewhat greater for planned attempts (nearly one-third substantial and nearly $60 \%$ either moderate or substantial) than unplanned attempts (about one-fourth substantial

$74.0 \%-79.7 \%$ accuracy based on their comparative scores on these risk indices-demonstrating a relatively high level of precision. The 2 indices for planned attempts were consistent across countries in that roughly half of planned attempts (sensitivity: $45.4 \%-51.3 \%$ ) were made by the roughly onethird to one-fourth of respondents classified as having the highest risk in both developed and developing countries $(22.1 \%-31.2 \%)$, while fewer than $10 \%$ of planned attempts were made by the roughly one-third to one-fourth of respondents classified as having the lowest risk $(27.2 \%-34.8 \%)$. Stated differently, roughly two-thirds of respondents classified by the risk indices as having the highest risk made attempts (positive predictive value: $66.8 \%-68.7 \%$ ). The 2 indices for unplanned attempts have smaller proportions of and nearly $50 \%$ either moderate or substantial). (Detailed results are available on request.)

\section{DISCUSSION}

This study documented 3 noteworthy results. First, we provided estimates of the 12-month prevalence of suicidal behaviors among adults (18+ years old) in 21 countries. A recent review of studies of the 12-month prevalence of suicidal behaviors reported widely varying estimates found in prior studies. ${ }^{2}$ The estimates obtained in the current study were in the lower end of these ranges for each suicidal behavior. This was most likely the result of 2 features of our study: we used conservative items for the assessment of each 
suicidal behavior (eg, presence of suicide ideation required that a person have "seriously" thought about committing suicide rather than having merely "thoughts of death" as in some prior studies), and we used large representative samples of respondents from the general population (ie, rather than small selective samples that may be at higher risk for suicidal behaviors, such as young adults or those in a clinical setting). Although it has been suggested that suicidal behaviors may differ between developed and developing countries, ${ }^{51,52}$ consistent with our prior report on the cross-national lifetime prevalence of suicidal behaviors ${ }^{1}$ we found no differences in 12-month prevalence between developed and developing countries. The prevalence estimates for suicide attempts documented in this study complement cross-national data on suicide mortality maintained by the $\mathrm{WHO}^{53}$ and suggest that across the countries examined here there are approximately 14.6 suicide attempts for every one suicide death (median ratio: 14.6; IQR: 9.1-53.7) - a ratio consistent with those documented in prior reports. ${ }^{54,55}$

Second, we identified risk factors for 12-month suicidal behaviors across both developed and developing countries. Replicating the results of prior studies, female sex, younger age, lower education and income, unmarried status, unemployment, parent psychopathology, childhood adversities, the presence of every mental disorder assessed, and psychiatric comorbidity all emerged as significant risk factors for suicidal behaviors in this study. ${ }^{7,56-58}$ Interestingly, analyses revealed that most of these factors are associated with suicide attempts because they are predictive of suicide ideation even though they do not significantly predict the occurrence of suicide attempts among those with suicide ideation. For instance, although the presence of a DSM-IV mental disorder was associated with significantly higher odds of experiencing suicide ideation in virtually every instance, few mental disorders predicted suicide attempts among those with ideation. Among those few disorders, conduct disorder emerged as the strongest and most consistent predictor of suicide attempts, with anxiety and substance use disorders also showing significant results in several instances. These findings are consistent with those from a recent study of the prediction of lifetime suicide attempts ${ }^{1}$ and suggest that disorders characterized by impulse-control and anxiety may be most important in predicting the transition from suicidal thoughts to suicide attempts.

Our analyses also add to the growing literature on the importance of prior history of suicidal behaviors in predicting subsequent suicide attempts. ${ }^{27,28,59}$ The current study extends earlier work on this topic by differentiating 2 processes involved in the transition from suicidal thoughts to attempts. In line with prior findings, a history of prior suicide attempt was found to be strongly predictive of 12-month suicide attempts. ${ }^{28,34,60}$ Our analysis adds to prior research by showing specificity in this process, though, such that a history of unplanned (impulsive) suicide attempts predicts subsequent unplanned attempts (but not planned ones), while a history of planned attempts predicts subsequent planned attempts (but not unplanned ones). This is an important specification for clinicians working with potentially suicidal patients, especially patients with a history of unplanned suicide attempts.

We also found that risk of the transition from suicidal thoughts to attempts was significantly lower among those who had thought of suicide in the past but never made an attempt than even among those who had never had suicidal thoughts before the past 12 months. This intriguing result, coupled with the earlier finding that more than $60 \%$ of the transitions from suicide ideation to attempt occur in the first year after onset of ideation, ${ }^{1}$ suggests that resisting the urge to make a suicide attempt when suicidal thoughts first occur is associated with decreased risk of acting on these thoughts when they return. An important next step is to study people with a history of ideation who never made a suicide attempt in greater detail in an effort to understand what characterizes such people (eg, good impulse control, low severity of suicide ideation) and what strategies they use to resist the urge to make a suicide attempt. Importantly, these findings should not be interpreted to mean that those who have thought about suicide in the past but not made an attempt are not at risk of making a future suicide attempt, but only that evidence of not having made a previous attempt despite having suicide ideation is a predictor of low risk of future attempts compared to people with more recent first onset of ideation. It is important for clinicians to conduct a thorough risk assessment with each patient encountered and to use ongoing monitoring of suicide risk. ${ }^{61-63}$

Third, and perhaps most important, we developed risk factor indices for 12-month suicide attempts tailored for planned versus unplanned attempts and with versions available for both developed and developing countries. Although only a handful of factors emerged as predictors of suicide attempts among ideators, our analyses revealed that all 4 summary risk indices using these factors showed good discrimination properties (as evidenced by moderate to substantial AUCs of 0.74-0.80) in the total sample that also performed quite well when applied to most developed countries and to a substantial minority of developing countries. These results suggest that the indices might prove useful in predicting suicide attempts in clinical settings; however, this remains an important question for future study. Although suicide prevention programs that include a focus on screening in order to identify people at elevated risk for suicide are among the only prevention programs that have shown an ability to decrease the rate of suicide death, ${ }^{64}$ such programs are not used in most clinical settings. What has been lacking is an empirically derived screening instrument that can be feasibly used in clinical settings to assess key risk factors and determine a person's level of risk for suicide attempt. Although it will be important to test the prospective predictive ability of these indices in actual clinical settings, the risk indices developed in this study represent an important initial step toward bridging the gap between the science and practice of suicide risk assessment.

Several additional features of the risk indices developed here warrant further comment. First, our risk indices had 
strong correlations with planned and unplanned attempts among suicide ideators from a large and heterogeneous set of developed and developing countries, suggesting these indices may have good generality in the prediction of suicide attempts-and indirectly supporting the cross-cultural validity of the WMH-CIDI measure used to assess these risk factors. Second, the performance of our risk indices was only slightly lower that the one developed using a much more homogenous sample ${ }^{34}$ and is similar to the AUC reported among a selective group of psychiatric patients. ${ }^{65}$ Our results also suggest that we may be able to predict suicide attempts with the same level of accuracy possible in other areas of medicine in which actuarial approaches that combine risk factors from multiple domains have proven more accurate than clinical prediction, such as in the prediction of violence and sexual offenses ${ }^{30,66}$ and the prediction of death from natural causes among the elderly. ${ }^{67}$ Third, and finally, it is important to note that these indices are not intended to serve as a comprehensive suicide assessment by themselves but instead may be best used to identify those at high risk for suicide attempt so that they can receive a more focused, in-depth assessment of current risk for suicidal behavior.

The results of this study should be interpreted with 4 important limitations in mind. First, our analysis was based on retrospective self-reports. This concern is limited somewhat by our focus on suicide attempts in only the past 12-months; however, it is possible that time-varying risk factors (eg, marital status, income) reported for the past 12-months may have changed after respondents' suicide attempts. Retrospective recall of childhood adversities and parental psychopathology might have been influenced by respondents' current mood or recent suicide attempt. ${ }^{68,69}$ Given these issues, these results should be considered preliminary until the risk indices developed are cross-validated prospectively. Second, although the overall response rate was at an acceptable level, response rates varied across countries and in some cases were below commonly accepted standards. We controlled for differential response using poststratification adjustments, but it is possible that response rates were related to the presence of suicidal behaviors or mental disorders, which could have biased cross-national comparisons. Third, there may have been cross-national differences in the willingness to report on suicidal behaviors and in the interpretation of items assessing risk factors. Significant efforts were dedicated to carefully translating and back-translating the WMH-CIDI used in this study in order to minimize such concerns ${ }^{36}$; however, differences in factors such as the stigma about suicide and childhood maltreatment are likely to persist cross-nationally despite these efforts. Fourth, although we examined a broad set of potential risk factors, many important factors were not included in this study. Psychotic disorders, although known to be associated with suicidal behavior, were not assessed because prior studies have shown that they are dramatically overestimated using structured interviews such as the WMH-CIDI. ${ }^{70,71}$ We also did not include many family history factors (eg, history of schizophrenia or bipolar disorder), psychological (eg, hopelessness), social (eg, lack of social support) or biologic (eg, serotonergic functioning) known to be associated with suicidal behaviors. Any one study cannot assess all such factors; however, the limited focus used is important to bear in mind when interpreting the results.

Author affiliations: Department of Health Care Policy, Harvard Medical School, Boston, Massachusetts (Dr Kessler, Mr Hwang, and Ms Sampson); National Institute of Psychiatry, Mexico City, Mexico (Drs Borges and Medina-Mora); Department of Psychology, Harvard University, Cambridge, Massachusetts (Dr Nock); Sant Joan de Deu-SSM, Centro de Investigación Biomédica en Red de Salud Mental, Instituto de Salud Carlos III, Barcelona, Spain (Dr Abad); Health Services Research Unit, Institut Municipal d'Investigació Mèdica, Hospital del Mar, Centro de Investigación Biomédica en Red (CIBER) de Epidemiología y Salud Pública, Barcelona, Spain (Dr Alonso); Section of Psychiatric Epidemiology, Institute of Psychiatry, School of Medicine, University of São Paulo, Brazil (Dr Andrade); Center for Public Mental Health, Gösing am Wagram, Austria (Dr Angermeyer); Christchurch School of Medicine \& Health Sciences, Otago, New Zealand (Dr Beautrais); State University of New York, Stony Brook (Dr Bromet); University Hospital Gasthuisberg, Leuven, Belgium (Dr Bruffaerts); Regional Health Care Agency, Emilia-Romagna Region, Bologna, Italy (Dr de Girolamo); Health System Research Department, National School of Public Health and Health Services Management, Bucharest, Romania (Dr Florescu); Department of Psychiatry, University College Hospital, Ibadan, Nigeria (Dr Gureje); Shenzhen Institute of Mental Health \& Shenzhen Kangning Hospital, Shenzhen, China (Dr Hu); Institute for Development, Research, Advocacy, and Applied Care, St George Hospital University Medical Center, Beirut Lebanon (Dr Karam); University of Paris Descartes and MGEN Foundation for Public Health, Paris, France (Dr KovessMasfety); Department of Psychiatry, The Chinese University of Hong Kong, HKSAR, China (Dr Lee); Director Research \& Planning, Ministry of Health, Mental Health Services, Jerusalem, Israel (Dr Levinson); University Medical Center Groningen, University of Groningen, the Netherlands (Dr Ormel); Colegio Mayor de Cundinamarca University, Bogotá, Colombia (Dr Posada-Villa); All India Institute of Medical Sciences, New Delhi, India (Dr Sagar); New Bulgarian University, Institute for Human Relations, Sofia, Bulgaria (Dr Tomov); Social Welfare and Environmental Department, Osumi Regional Promotion Bureau, Kagoshima Prefecture, Japan (Dr Uda); and Harvard School of Public Health, Boston, Massachusetts (Dr Williams).

Potential conflicts of interest: Dr Kessler has been a consultant for GlaxoSmithKline, Kaiser Permanente, Pfizer, sanofi-aventis, Shire, and Wyeth-Ayerst; has served on advisory boards for Eli Lilly and WyethAyerst; and has received research support for his epidemiologic studies from Bristol-Myers Squibb, Eli Lilly, GlaxoSmithKline, Johnson \& Johnson, Ortho-McNeil, Pfizer, and sanofi-aventis. The remaining authors report no financial or other relationship relevant to the subject of this article.

Funding/support: These activities were supported by the US National Institute of Mental Health (NIMH) (R01MH070884, R01MH077883), the John D. and Catherine T. MacArthur Foundation, the Pfizer Foundation, the US Public Health Service (R13-MH066849, R01-MH069864, and R01 DA016558), the Fogarty International Center (FIRCA R03-TW006481), the Pan American Health Organization, Eli Lilly, Ortho-McNeil, GlaxoSmithKline, and Bristol-Myers Squibb. A complete list of WMH publications can be found at http://www.hcp.med.harvard.edu/wmh/. The São Paulo Megacity Mental Health Survey is supported by the State of São Paulo Research Foundation Thematic Project Grant (03/00204-3). The Chinese World Mental Health Survey Initiative is supported by Pfizer. The Shenzhen Mental Health Survey is supported by the Shenzhen Bureau of Health and the Shenzhen Bureau of Science, Technology, and Information. The Colombian National Study of Mental Health is supported by the Ministry of Social Protection. The European Study of the Epidemiology of Mental Disorders project is funded by the European Commission (contracts QLG5-1999-01042; SANCO 2004123); the Piedmont Region (Italy); Fondo de Investigación Sanitaria, Instituto de Salud Carlos III, Spain (FIS 00/0028); Ministerio de Ciencia y Tecnología, Spain (SAF 2000-158-CE); Departament de Salut, Generalitat de Catalunya, Spain, Instituto de Salud Carlos III (CIBER CB06/02/0046, RETICS RD06/0011 REM-TAP); and other local agencies and by an unrestricted educational grant from GlaxoSmithKline. The World Mental Health India Survey was funded by WHO (India) and helped by Dr R. Chandrasekaran, the Jawaharlal Institute of Postgraduate Medical Education \& Research. The Israel National Health Survey is funded by 
the Ministry of Health with support from the Israel National Institute for Health Policy and Health Services Research and the National Insurance Institute of Israel. The World Mental Health Japan Survey is supported by the Grant for Research on Psychiatric and Neurological Diseases and Mental Health (H13-SHOGAI-023, H14-TOKUBETSU-026, H16-KOKORO-013) from the Japan Ministry of Health, Labour and Welfare. The Lebanese National Mental Health Survey is supported by the Lebanese Ministry of Public Health, the WHO (Lebanon), Fogarty International, Act for Lebanon, anonymous private donations to the Institute for Development, Research, Advocacy \& Applied Care, Lebanon, and unrestricted grants from Janssen Cilag, Eli Lilly, GlaxoSmithKline, Roche, and Novartis. The Mexican National Comorbidity Survey is supported by The National Institute of Psychiatry Ramon de la Fuente (INPRFMDIES 4280) and by the National Council on Science and Technology (CONACyT-G30544- H), with supplemental support from the Pan American Health Organization. Te Rau Hinengaro: The New Zealand Mental Health Survey is supported by the New Zealand Ministry of Health, Alcohol Advisory Council, and the Health Research Council. The Nigerian Survey of Mental Health and Well-Being is supported by the WHO (Geneva), the WHO (Nigeria), and the Federal Ministry of Health, Abuja, Nigeria. The Romania WMH study projects "Policies in Mental Health Area" and "National Study Regarding Mental Health and Services Use" were carried out by the National School of Public Health \& Health Services Management (former National Institute for Research \& Development in Health), with technical support of Metro Media Transilvania, the National Institute of Statistics-National Centre for Training in Statistics. Cheyenne Services SRL and Statistics Netherlands were funded by the Ministry of Public Health (former Ministry of Health) with supplemental support of Eli Lilly Romania SRL. The South Africa Stress and Health Study is supported by the NIMH (R01-MH059575) and the National Institute of Drug Abuse (NIDA) with supplemental funding from the South African Department of Health and the University of Michigan. The Ukraine Comorbid Mental Disorders During Periods of Social Disruption study is funded by the NIMH (R01-MH61905). The US National Comorbidity Survey Replication is supported by the NIMH (U01-MH60220) with supplemental support from the NIDA, the Substance Abuse and Mental Health Services Administration, the Robert Wood Johnson Foundation (grant 044708), and the John W. Alden Trust. Acknowledgments: These surveys are carried out in conjunction with the World Health Organization World Mental Health (WMH) Survey Initiative. The authors thank the WMH staff for assistance with instrumentation, fieldwork, and data analysis.

\section{REFERENCES}

1. Nock MK, Borges G, Bromet EJ, et al. Cross-national prevalence and risk factors for suicidal ideation, plans and attempts. Br J Psychiatry. 2008; 192(2):98-105.

2. Nock MK, Borges G, Bromet EJ, et al. Suicide and suicidal behavior. Epidemiol Rev. 2008;30(1):133-154.

3. Fawcett J, Scheftner WA, Fogg L, et al. Time-related predictors of suicide in major affective disorder. Am J Psychiatry. 1990;147(9):1189-1194.

4. Neeleman J, de Graaf R, Vollebergh W. The suicidal process; prospective comparison between early and later stages. J Affect Disord. 2004;82(1): $43-52$

5. Schmidtke A, Bille-Brahe U, DeLeo D, et al. Attempted suicide in Europe: rates, trends and sociodemographic characteristics of suicide attempters during the period 1989-1992: results of the WHO/EURO Multicentre Study on Parasuicide. Acta Psychiatr Scand. 1996;93(5):327-338.

6. Brown GK, Beck AT, Steer RA, et al. Risk factors for suicide in psychiatric outpatients: a 20-year prospective study. J Consult Clin Psychol. 2000; 68(3):371-377.

7. Kessler RC, Borges G, Walters EE. Prevalence of and risk factors for lifetime suicide attempts in the National Comorbidity Survey. Arch Gen Psychiatry. 1999;56(7):617-626.

8. Mann JJ, Waternaux C, Haas GL, et al. Toward a clinical model of suicidal behavior in psychiatric patients. Am J Psychiatry. 1999;156(2):181-189.

9. Pokorny AD. Prediction of suicide in psychiatric patients: report of a prospective study. Arch Gen Psychiatry. 1983;40(3):249-257.

10. Prinstein MJ, Nock MK, Simon V, et al. Longitudinal trajectories and predictors of adolescent suicidal ideation and attempts following inpatient hospitalization. J Consult Clin Psychol. 2008;76(1):92-103.

11. Kessler RC, Berglund P, Borges G, et al. Trends in suicide ideation, plans, gestures, and attempts in the United States, 1990-1992 to 2001-2003. JAMA. 2005;293(20):2487-2495.

12. Insel TR. Translational research in the decade of discovery.
Horm Behav. 2006;50(4):504-505.

13. Zerhouni EA. Translational and clinical science-time for a new vision. N Engl J Med. 2005;353(15):1621-1623.

14. Bertolote JM, Fleischmann A, De Leo D, et al. Suicide attempts, plans, and ideation in culturally diverse sites: the WHO SUPRE-MISS community survey. Psychol Med. 2005;35(10):1457-1465.

15. Platt S, Bille-Brahe U, Kerkhof A, et al. Parasuicide in Europe: the WHO/ EURO multicentre study on parasuicide, I: introduction and preliminary analysis for 1989. Acta Psychiatr Scand. 1992;85(2):97-104.

16. Weissman MM, Bland RC, Canino GJ, et al. Prevalence of suicide ideation and suicide attempts in nine countries. Psychol Med. 1999;29(1): 9-17.

17. Brent DA, Mann JJ. Family genetic studies, suicide, and suicidal behavior. Am J Med Genet C Semin Med Genet. 2005;133C(1):13-24.

18. Mann JJ, Bortinger J, Oquendo MA, et al. Family history of suicidal behavior and mood disorders in probands with mood disorders. Am J Psychiatry. 2005;162(9):1672-1679.

19. Dube SR, Anda RF, Felitti VJ, et al. Childhood abuse, household dysfunc tion, and the risk of attempted suicide throughout the life span: findings from the Adverse Childhood Experiences Study. JAMA. 2001;286(24): 3089-3096.

20. World Bank. Data and statistics. 2008; http://go.worldbank.org/ D7SN0B8YU0. Accessed May 12, 2009.

21. Molnar BE, Berkman LF, Buka SL. Psychopathology, childhood sexual abuse and other childhood adversities: relative links to subsequent suicidal behaviour in the US. Psychol Med. 2001;31(6):965-977.

22. Gould MS, King R, Greenwald S, et al. Psychopathology associated with suicidal ideation and attempts among children and adolescents. J Am Acad Child Adolesc Psychiatry. 1998;37(9):915-923.

23. Petronis KR, Samuels JF, Moscicki EK, et al. An epidemiologic investigation of potential risk factors for suicide attempts. Soc Psychiatry Psychiatr Epidemiol. 1990;25(4):193-199.

24. Shaffer D, Gould MS, Fisher P, et al. Psychiatric diagnosis in child and adolescent suicide. Arch Gen Psychiatry. 1996;53(4):339-348.

25. Vijayakumar L, Rajkumar S. Are risk factors for suicide universal? a case-control study in India. Acta Psychiatr Scand. 1999;99(6):407-411.

26. Weissman MM, Klerman GL, Markowitz JS, et al. Suicidal ideation and suicide attempts in panic disorder and attacks. N Engl J Med. 1989; 321(18):1209-1214.

27. Goldstein RB, Black DW, Nasrallah A, et al. The prediction of suicide: sensitivity, specificity, and predictive value of a multivariate model applied to suicide among 1906 patients with affective disorders. Arch Gen Psychiatry. 1991;48(5):418-422.

28. Joiner TE Jr, Conwell Y, Fitzpatrick KK, et al. Four studies on how past and current suicidality relate even when "everything but the kitchen sink" is covaried. J Abnorm Psychol. 2005;114(2):291-303.

29. Dawes RM, Faust D, Meehl PE. Clinical versus actuarial judgment. Science. 1989;243(4899):1668-1674.

30. Harris GT, Rice ME. Actuarial assessment of risk among sex offenders. Ann N Y Acad Sci. 2003;989:198-210, discussion 236-246.

31. Harris GT, Rice ME, Camilleri JA. Applying a forensic actuarial assessment (the Violence Risk Appraisal Guide) to nonforensic patients. J Interpers Violence. 2004;19(9):1063-1074.

32. Hilton NZ, Harris GT, Rice ME, et al. A brief actuarial assessment for the prediction of wife assault recidivism: the Ontario domestic assault risk assessment. Psychol Assess. 2004;16(3):267-275.

33. Mossman D. Assessing predictions of violence: being accurate about accuracy. J Consult Clin Psychol. 1994;62(4):783-792.

34. Borges G, Angst J, Nock MK, et al. A risk index for 12-month suicide attempts in the National Comorbidity Survey Replication (NCS-R). Psychol Med. 2006;36(12):1747-1757.

35. Pennell B-E, Mneimneh Z, Bowers A, et al. Implementation of the World Mental Health Surveys. In: Kessler RC, Üstün TB, eds. The WHO World Mental Health Surveys: Global Perspectives on the Epidemiology of Mental Disorders. New York, NY: Cambridge University Press; 2008:33-57.

36. Kessler RC, Ustün TB. The World Mental Health (WMH) Survey Initiative Version of the World Health Organization (WHO) Composite International Diagnostic Interview (CIDI). Int J Methods Psychiatr Res. 2004;13(2):93-121.

37. Turner CF, Ku L, Rogers SM, et al. Adolescent sexual behavior, drug use, and violence: increased reporting with computer survey technology. Science. 1998;280(5365):867-873.

38. Andreasen NC, Endicott J, Spitzer RL, et al. The family history method using diagnostic criteria: reliability and validity. Arch Gen Psychiatry. 1977;34(10):1229-1235.

39. Kendler KS, Davis CG, Kessler RC. The familial aggregation of common 
psychiatric and substance use disorders in the National Comorbidity Survey: a family history study. Br J Psychiatry. 1997;170(6):541-548.

40. Kessler RC, Davis CG, Kendler KS. Childhood adversity and adult psychiatric disorder in the US National Comorbidity Survey. Psychol Med. 1997;27(5):1101-1119.

41. First MB, Spitzer RL, Gibbon M, et al. Structured Clinical Interview for DSM-IV Axis I Disorders, Research Version, Non-Patient Edition (SCID-I/NP). New York, NY: Biometrics Research, New York State Psychiatric Institute; 2002.

42. Haro JM, Arbabzadeh-Bouchez S, Brugha TS, et al. Concordance of the Composite International Diagnostic Interview Version 3.0 (CIDI 3.0) with standardized clinical assessments in the WHO World Mental Health surveys. Int J Methods Psychiatr Res. 2006;15(4):167-180.

43. Hosmer DW, Lemeshow S. Applied Logistic Regression. New York, NY: Wiley \& Sons; 1989.

44. Wolter KM. Introduction to Variance Estimation. New York, NY: Springer-Verlag; 1985.

45. Research Triangle Institute. SUDAAN: Professional Software for Survey Data Analysis. 8.01 ed. Research Triangle Park, NC: Research Triangle Institute; 2002

46. Guyatt G, Rennie D. User's Guide to the Medical Literature: A Manual for Evidence-Based Clinical Practice. Chicago, IL: AMA Press; 2001.

47. Hanley JA, McNeil BJ. The meaning and use of the area under a receiver operating characteristic (ROC) curve. Radiology. 1982;143(1):29-36.

48. Cohen J. A coefficient of agreement for nominal scales. Educ Psychol Meas. 1960;20(1):37-46.

49. Kraemer HC, Morgan GA, Leech NL, et al. Measures of clinical significance. J Am Acad Child Adolesc Psychiatry. 2003;42(12):1524-1529.

50. Landis JR, Koch GG. The measurement of observer agreement for categorical data. Biometrics. 1977;33(1):159-174.

51. Vijayakumar L, Nagaraj K, Pirkis J, et al. Suicide in developing countries, (1): frequency, distribution, and association with socioeconomic indicators. Crisis. 2005;26(3):104-111.

52. Vijayakumar L, Pirkis J, Whiteford H. Suicide in developing countries (3): prevention efforts. Crisis. 2005;26(3):120-124.

53. World Health Organization. WHO Mortality Database: Tables. 2009; http://www.who.int/healthinfo/morttables/en/. Accessed April 24, 2009.

54. Centers for Disease Control. Web-based Injury Statistics Query and Reporting System (WISQARS) Fatal Injuries: Mortality Reports. 2008; http://webappa.cdc.gov/sasweb/ncipc/mortrate.html. Accessed April 24, 2008.

55. Centers for Disease Control. Web-based Injury Statistics Query and Reporting System (WISQARS) Nonfatal Injuries: Nonfatal Injury Reports. 2008; http://webappa.cdc.gov/sasweb/ncipc/nfirates.html. Accessed April 24, 2009.

56. Borges G, Angst J, Nock MK, et al. Risk factors for the incidence and persistence of suicide-related outcomes: a 10-year follow-up study using the National Comorbidity Surveys. J Affect Disord. 2008;105(1-3):25-33.

57. Moscicki EK. Epidemiology of suicide. In: Jacobs DG, ed. The Harvard Medical School Guide to Suicide Assessment and Intervention. San Francisco, CA: Jossey-Bass; 1999:40-51.

58. Nock MK, Kessler RC. Prevalence of and risk factors for suicide attempts versus suicide gestures: analysis of the National Comorbidity Survey. J Abnorm Psychol. 2006;115(3):616-623.

59. Gould MS, Greenberg T, Velting DM, et al. Youth suicide risk and preventive interventions: a review of the past 10 years. J Am Acad Child Adolesc Psychiatry. 2003;42(4):386-405.

60. Kuo WH, Gallo JJ. Completed suicide after a suicide attempt. Am J Psychiatry. 2005;162(3):633.

61. American Academy of Child and Adolescent Psychiatry. Practice parameter for the assessment and treatment of children and adolescents with suicidal behavior. J Am Acad Child Adolesc Psychiatry. 2001;40(suppl): 24S-51S.

62. American Psychiatric Association. Practice Guideline for the Assessment and Treatment of Patients With Suicidal Behaviors. Am J Psychiatry. 2003;160(suppl):1-60.

63. Nock MK, Wedig MM, Janis IB, et al. Self-injurious thoughts and behaviors. In: Hunsely J, Mash E, eds. A Guide to Assessments That Work. New York, NY: Oxford University Press; 2008:158-177.

64. Mann JJ, Apter A, Bertolote J, et al. Suicide prevention strategies: a systematic review. JAMA. 2005;294(16):2064-2074.

65. Mann JJ, Ellis SP, Waternaux CM, et al. Classification trees distinguish suicide attempters in major psychiatric disorders: a model of clinical decision making. J Clin Psychiatry. 2008;69(1):23-31.

66. Monahan J, Steadman HJ, Robbins PC, et al. An actuarial model of violence risk assessment for persons with mental disorders. Psychiatr Serv. 2005;56(7):810-815.

67. Lee SJ, Lindquist K, Segal MR, et al. Development and validation of a prognostic index for 4-year mortality in older adults. JAMA. 2006;295(7): 801-808.

68. Henry B, Moffitt TE, Caspi A, et al. On the "remembrance of things past:" a longitudinal evaluation of the retrospective method. Psychol Assess. 1994;6(2):92-101.

69. Schacter DL. The seven sins of memory: insights from psychology and cognitive neuroscience. Am Psychol. 1999;54(3):182-203.

70. Eaton WW, Romanoski A, Anthony JC, et al. Screening for psychosis in the general population with a self-report interview. J Nerv Ment Dis. 1991;179(11):689-693.

71. Kendler KS, Gallagher TJ, Abelson JM, et al. Lifetime prevalence, demographic risk factors, and diagnostic validity of nonaffective psychosis as assessed in a US community sample. The National Comorbidity Survey. Arch Gen Psychiatry. 1996;53(11):1022-1031.

72. American Psychiatric Association. Diagnostic and Statistical Manual of Mental Disorders, Fourth Edition. Washington, DC: American Psychiatric Association; 1994. 